\title{
Mechanistic studies of methanol-to-hydrocarbons conversion on diffusion-free MFI samples
}

\author{
Rachit Khare and Aditya Bhan * \\ Department of Chemical Engineering and Materials Science \\ University of Minnesota - Twin Cities \\ 421 Washington Avenue SE \\ Minneapolis, Minnesota 55455 \\ $U S A$
}

* Corresponding author.

E-mail addresses: khare014@umn.edu (R. Khare), abhan@umn.edu (A. Bhan) 


\begin{abstract}
Self-pillared pentasil MFI ( 1 nm diffusion length) exhibited low ethene selectivity (1.1\%) at $<100 \%$ conversion for the catalytic reaction of dimethyl ether (DME) at $723 \mathrm{~K}$ and $\sim 60 \mathrm{kPa}$ DME pressure suggesting that the aromatics-based catalytic cycle is intrinsically suppressed in the pores of MFI under these reaction conditions. Co-feeding toluene or $p$-xylene with DME increased the number of chain carriers of the aromatics-based cycle thereby enhancing its propagation and resulting in a 2-3 fold increase in ethene selectivity. Co-feeding propene or 1hexene, however, did not have an effect on the product distribution, suggesting that the olefinsbased hydrocarbon pool is saturated in the pores of MFI. High temperature $(723 \mathrm{~K})$ and low DME space-velocity $\left(\leq 2.5 \mathrm{~mol} \mathrm{C}[\mathrm{mol} \mathrm{Al-s}]^{-1}\right)$, conditions resulting in complete DME/methanol conversion, result in a two-staged catalyst bed: the first stage performs methanol-tohydrocarbons chemistry in the presence of DME/methanol; the second stage begins after 100\% DME conversion is achieved and is characterized by the absence of DME/methanol. The aromatics-based methylation/cracking cycle is absent in the second stage as methylbenzenes cannot dealkylate in the absence of DME/methanol, and the dominant pathway to ethene formation under these reaction conditions is olefin inter-conversion.
\end{abstract}

Keywords: Methanol-to-hydrocarbons, aromatics-based catalytic cycle, olefins-based catalytic cycle, MFI, diffusion-free, ethene selectivity, low space-velocity, high conversion 


\section{Introduction}

Catalytic conversion of methanol or dimethyl ether (DME), its dehydration product, on MFI proceeds via the indirect hydrocarbon-pool mechanism. [1-6] In this mechanism, unsaturated hydrocarbons present inside the zeolite pores, together with the Brønsted acid sites, act as co-catalysts for the production of hydrocarbons and result in the complex hydrocarbon distribution observed in the effluent. [7-14] The hydrocarbon-pool mechanism comprises two distinct, but not independent, catalytically active reaction cycles: the aromatics- and olefinsbased methylation/cracking cycles. In the aromatics-based catalytic cycle, methylbenzenes (MBs) undergo methylation in the presence of a methylating agent like DME/methanol to form higher MB homologues, which subsequently dealkylate light olefins to complete the catalytic cycle. In the olefins-based catalytic cycle, olefins methylate to form higher olefins, which can either crack to form lighter olefins or undergo cyclization and hydrogen-transfer to form aromatics. Both these catalytic cycles are simultaneously active inside the pores of MFI, and the relative propagation of these two cycles determines the hydrocarbon distribution observed in the effluent. [15, 16] Ethene, together with higher olefins, aromatics, and branched/linear paraffins, is one of the major products of methanol-to-hydrocarbons (MTH) conversion on MFI.

Mole et al. [17] performed isotopic experiments that involved the co-reaction of ${ }^{13} \mathrm{C}$ labeled benzene or toluene with unlabeled methanol on H-ZSM-5 at 552-583 K and showed that isotopically labeled carbon atoms from the aromatics were incorporated into ethene observed in the effluent. Bjørgen [18], Ilias [15], and Mikkelsen [19], also reported similar results from isotopic experiments on MFI, MOR, and BEA zeolites suggesting that ethene is formed from MBs at $623 \mathrm{~K}$ or lower reaction temperatures. Svelle, Bjørgen and coworkers performed isotopic 
switching experiments on H-ZSM-5 at $623 \mathrm{~K}$ in which ${ }^{12} \mathrm{C}$-methanol was reacted for 18 minutes followed by a rapid switch to ${ }^{13} \mathrm{C}$-methanol. [20-22] Their results showed that the incorporation of ${ }^{13} \mathrm{C}$ in ethene after the switch was similar to ${ }^{13} \mathrm{C}$-incorporation in the MBs thereby suggesting that ethene and MBs originate from the same aromatics-based catalytic cycle. In contrast, ${ }^{13} \mathrm{C}$ incorporation in $\mathrm{C}_{3}+$ olefins matched each other but not with ethene, suggesting that $\mathrm{C}_{3}+$ olefins, and not ethene, constitute the olefins-based catalytic cycle. [20-22] Abbot and Wojciechowski investigated catalytic cracking of $\mathrm{C}_{5}-\mathrm{C}_{9}$ linear alkenes on H-ZSM-5 at $623-678 \mathrm{~K}$ and showed that ethene is nearly absent as a primary cracking product of these linear alkenes further suggesting that ethene is not a product of the olefins-based catalytic cycle. [23, 24] Recently, Ilias et al. [25] concluded, on the basis of isotopic experiments where ${ }^{12} \mathrm{C}$ - or ${ }^{13} \mathrm{C}$-labeled DME was co-reacted with isotopically labeled toluene, $p$-xylene, or ethylbenzene, that 1,2,4-triMB and 1,2,4,5-tetraMB are the dominant aromatic precursors to ethene and propene on H-ZSM-5 at 523-723 K reaction temperature.

Dessau and LaPierre reacted ${ }^{13} \mathrm{C}$-methanol in the presence of ${ }^{12} \mathrm{C}$-propene or ${ }^{12} \mathrm{C}-1$ hexene on H-ZSM-5 at 573-623 K and observed the presence of both labeled and unlabeled carbon atoms in ethene. [7] Isotopic experiments by Mole et al. [26], which involved the coreaction of ${ }^{13} \mathrm{C}$-labeled methanol with unlabeled $n$-propanol or $t$-butanol (which readily dehydrate on zeolites to form corresponding olefins) on H-ZSM-5 at 575-582 K, showed the incorporation of carbon atoms from the unlabeled alcohol into ethene present in the effluent, thereby suggesting that ethene is formed from olefins present in the olefins-based catalytic cycle. Chen et al. [27] investigated $\beta$-scission of hexene isomers on H-ZSM-5 at $783 \mathrm{~K}$ and showed that $\sim 9 \%$ ethene is present in the cracking products at $<15 \%$ conversion suggesting ethene 
observed in MTH conversion under conditions where DME/methanol is depleted could arise from olefin cracking reactions. Sun et al. [28] investigated methanol conversion on ZSM-5 at $723 \mathrm{~K}$ and reported that under industrially relevant reaction conditions for MTH conversion, hexene cracking is an important route for ethene formation and that the aromatics-based catalytic cycle is not mechanistically linked with ethene. These experimental observations suggest that ethene is a product of both the aromatics- and the olefins-based catalytic cycles; however, the dominant pathways to ethene formation on MFI depend on the applied reaction conditions.

The observed product distribution in MTH conversion can be interpreted as a consequence of the relative extents of propagation of the aromatics- and the olefins-based catalytic cycles inside the pores of MFI. Ilias et al. $[15,16]$ showed that co-feeding small amounts of propene $(4 \mathrm{kPa})$ with $70 \mathrm{kPa}$ DME on $\mathrm{H}-\mathrm{ZSM}-5$ at $548-623 \mathrm{~K}$ increased the propagation of the olefins-based catalytic cycle and resulted in higher selectivity towards $\mathrm{C}_{3}$ and $\mathrm{C}_{4}-\mathrm{C}_{7}$ aliphatic hydrocarbons. Experimental investigation by Sun et al. [29], on the other hand, showed that co-feeding $\mathrm{C}_{3}-\mathrm{C}_{6}$ olefins $(10-40 \mathrm{C} \%)$ with methanol at higher temperature $(723 \mathrm{~K})$ and higher DME conversion conditions did not selectively enhance the propagation of the olefins-based catalytic cycle and no increase in $\mathrm{C}_{3}+$ selectivity was observed. Sun et al. [29] suggested that addition of olefins enhances the aromatization of higher olefins, which increases the concentration of aromatics inside the zeolite pores, thereby enhancing the propagation of both the aromatics-based and the olefins-based catalytic cycles. The relative propagation of the olefins-based catalytic cycle was therefore not affected by the olefin co-feed. Both Ilias et al. $[15,16]$ and Sun et al. [29], in independent studies, reported that co-reacting MBs with methanol/DME on H-ZSM-5 under a wide-range of reaction temperatures (548-723 K) enhances 
the propagation of the aromatics-based catalytic cycle and results in higher selectivity toward MBs as well as ethene.

Reaction parameters such as the reaction temperature and space-velocity have an effect on the observed product distribution of MTH conversion. Chang and Silvestri investigated the effects of DME/methanol space-velocity on MTH conversion on ZSM-5 and noted that $\mathrm{C}_{2}-\mathrm{C}_{5}$ olefin selectivity decreases while the selectivity towards paraffins, $\mathrm{C}_{6}+$ olefins, and aromatics, increases with decreasing DME/methanol space-velocity. [30] Chang et al. [31] reported, in independent studies, that $\mathrm{C}_{2}-\mathrm{C}_{3}$ olefin selectivity decreases while selectivity to paraffins and aromatics increases with a decrease in methanol space-velocity after $100 \% \mathrm{DME} / \mathrm{methanol}$ conversion was achieved over H-ZSM-5 at $773 \mathrm{~K}$. Chang and Silvestri also investigated the effects of reaction temperature $(533-841 \mathrm{~K})$ on the product distribution of MTH conversion on H-ZSM-5 at a fixed liquid hourly space-velocity. [30] The conversion of DME/methanol increased with reaction temperature and reached 100\% between 613 and $648 \mathrm{~K}$. At lower temperatures, $\mathrm{C}_{2}-\mathrm{C}_{5}$ olefins were the predominant products; an increase in temperature was accompanied by an increase in the formation of aromatics suggesting that secondary reactions like hydrogen-transfer and cyclization become predominant at higher temperatures. Ilias et al. [16] also studied the effects of temperature $(573-723 \mathrm{~K})$ on MTH selectivity at $<100 \%$ DME conversion and showed that ethene selectivity as well as MBs selectivity decreases with an increase in the reaction temperature. Ilias et al. [16] proposed that the decrease in ethene selectivity with increasing reaction temperature is a result of a decrease in the extent of propagation of the aromatics-based catalytic cycle relative to the olefins-based catalytic cycle. The propagation of the aromatics-based cycle is suppressed at higher temperatures because of a 
decrease in the number of chain carriers of the aromatics-based catalytic cycle. At $723 \mathrm{~K}$, higher olefins prefer to crack or desorb rather than cyclize and undergo hydrogen-transfer reactions, thereby decreasing the concentration of aromatics inside the zeolite pores, which suppresses the propagation of the aromatics-based catalytic cycle.

Crystallite size of MFI also affects the selectivity of MTH conversion by altering the relative extents of propagation of the aromatics- and the olefins-based catalytic cycles. Sugimoto et al. [32] showed that ethene selectivity increased from $\sim 1 \%$ in ZSM-5 with $\sim 200 \mathrm{~nm}$ crystallites to $13 \%$ in H-ZSM-5 with 3-4 $\mu$ m crystallites. Rownaghi et al. [33, 34] investigated MTH conversion on H-ZSM-5 with varying crystallite sizes at $643 \mathrm{~K}$ and observed that ethene selectivity increased from $6.6 \%$ in H-ZSM-5 nanocrystals ( $\sim 120 \mathrm{~nm}$ crystallites) to $9.6 \%$ in a conventional MFI catalyst with larger crystallites (wide-range). Bleken and coworkers reported that MFI nanosheets, which were only one unit cell thick $(\sim 2 \mathrm{~nm})$ along the $b$-axis, exhibited lower selectivity towards $\mathrm{C}_{2}$ hydrocarbons than a conventional ZSM-5 catalyst at $623 \mathrm{~K}$. [35] In a recent report, we demonstrated that ethene selectivity, for the catalytic conversion of DME on MFI at $623 \mathrm{~K}$, increases monotonically with increasing crystallite size of MFI. [36] The increase in ethene selectivity with increasing crystallite size was attributed to an increase in the intracrystalline residence time of MBs, which enhances the propagation of the aromatics-based catalytic cycle and results in higher ethene selectivity. [36]

The relative propagation of the aromatics- and olefins-based catalytic cycles in MTH conversion on MFI is affected by DME/methanol space-velocity, reaction temperature, presence of aromatic/olefin co-feed, as well as the crystallite size of MFI, which has resulted in contradictory mechanistic interpretations. We report, in this study, the intrinsic propagation of 
the aromatics- and the olefins-based catalytic cycles inside the pores MFI, assessed using diffusion-free MFI samples, and the contribution of these cycles towards the formation of ethene, at $723 \mathrm{~K}$ and $<100 \%$ conversion. DME conversion was also investigated under low DME spacevelocity $\left(\leq 2.5 \mathrm{~mol} \mathrm{C}[\mathrm{mol} \mathrm{Al-s}]^{-1}\right)$ conditions, which resulted in complete DME/methanol conversion. Diffusion-free MFI samples, specifically, self-pillared pentasil (SPP) MFI ( 1 nm diffusion length) and 3DOm-i MFI ( 20 nm diffusion length), were compared to a conventional MFI sample (Conv MFI, from Zeolyst International Inc., $\sim 250 \mathrm{~nm}$ diffusion length). Our studies on these samples allow us to infer that (i) the number of chain carriers of the olefins-based catalytic cycle is saturated inside the pores of MFI at $<100 \%$ DME conversion, the aromaticsbased catalytic cycle is suppressed due to low concentration of MBs, and that the low ethene selectivity on diffusion-free MFI samples (1-3\%) can be enhanced 2-4 fold by co-processing aromatics like toluene or $p$-xylene with DME, and (ii) at space-velocities lower than those required to achieve complete DME conversion $\left(\leq 2.5 \mathrm{~mol} \mathrm{C}[\mathrm{mol} \mathrm{Al}-\mathrm{s}]^{-1}\right)$, the first stage of the catalyst bed performs MTH chemistry in the presence of DME/methanol; the second stage begins after complete DME/methanol is consumed and the aromatic methylation/cracking cycle is shut down in this stage of the catalyst bed, Downstream olefin inter-conversion reactions, however, continue to propagate and produce ethene in the second stage of the catalyst bed.

\section{Experimental methods}

\subsection{Catalyst preparation}

SPP (Self-pillared pentasil) MFI and 3DOm-i MFI zeolite samples were synthesized according to the procedures described in reference [37]. Detailed structural and chemical characterization of these samples is described in the Supplementary Information section of 
reference [37]. The conventional MFI sample was acquired from Zeolyst International (CBV 8014, $\mathrm{SiO}_{2} / \mathrm{Al}_{2} \mathrm{O}_{3}=80$, denoted as Conv MFI) in its ammonium-form.

The zeolite samples were converted to their respective protonated forms by treating in $1.67 \mathrm{~cm}^{3} \mathrm{~s}^{-1}$ dry air (Minneapolis Oxygen, 20-21\% $\mathrm{O}_{2},<10 \mathrm{ppm} \mathrm{H}_{2} \mathrm{O}$ ) at $823 \mathrm{~K}$ for $4 \mathrm{~h}$. The temperature was increased from ambient to $823 \mathrm{~K}$ in $8 \mathrm{~h}$ and was held at $823 \mathrm{~K}$ for $4 \mathrm{~h}$. The samples were then pressed into pellets, crushed, and sieved between 40 - and 80 -mesh sieves to obtain aggregate particles with uniform size between 180 and $425 \mu \mathrm{m}$. In some cases, quartz sand (Acros Organics) was used for diluting the catalyst bed to prevent temperature rise due to exothermic reactions. Prior to its use, the quartz sand was washed with $1 \mathrm{M}$ nitric acid (SigmaAldrich), then rinsed several times with deionized water, dried, and sieved between 40- and 80mesh sieves.

\subsection{Structural and chemical characterization}

Elemental composition of the zeolite samples was determined by inductively coupled plasma-optical emission spectrometry (ICP-OES) performed by Galbraith Laboratories, Inc. The analytical method used was GLI procedure ME-70 accredited by the American Association for Laboratory Accreditation (A2LA), certificate number 2777.01.

Zhang et al. [37] estimated the diffusion length in SPP MFI and 3DOm-i MFI samples. Khare et al. [36] determined the diffusion length in Conv MFI sample by scanning electron microscopy (SEM). The analysis was performed on a JEOL 6700 field emission gun scanning electron microscope and the sample was coated with a thin layer of platinum before analysis. [36] 
The fraction of external Brønsted acid sites in SPP MFI, 3DOm-i MFI, and Conv MFI, was estimated by Zhang et al. [37] from the ratio of the number of Brønsted acid sites determined by 2,6-di-tert-butylpyridine titration and the number of Brønsted acid sites determined by DME titration.

\subsection{Catalytic reactions of dimethyl ether}

A stainless steel packed-bed reactor (0.25 in o.d.; 0.215 in i.d.), equipped with a concentric thermal well (0.0625 in o.d., 0.0485 in i.d.), was used to carry out the catalytic reactions. Isothermal conditions were maintained in the catalyst bed using a heating coil (ARi Industries Inc., AeroRod ${ }^{\circledR}$ heating assembly) regulated by a Watlow 96 series temperature controller. Temperature of the catalyst bed was measured using a K-type thermocouple (Omega Engineering) inserted into the concentric thermal well. Prior to every reaction, the catalyst was pre-treated in situ in $1.67 \mathrm{~cm}^{3} \mathrm{~s}^{-1}$ helium (Minneapolis Oxygen, 99.995\% purity) at $823 \mathrm{~K}$ for 4 h. The temperature was increased from ambient to $823 \mathrm{~K}$ in $8 \mathrm{~h}$ and was held at $823 \mathrm{~K}$ for $4 \mathrm{~h}$.

The reactant stream consisted of dimethyl ether (Matheson Tri-Gas, 99.5\% purity) and a mixture of methane and argon (Airgas, 10\% methane, 90\% argon) that was used as an internal standard for the gas chromatograph. In some cases helium (Minneapolis Oxygen, 99.995\% purity) was used in balance to keep the concentration of the internal standard comparable to that of the reaction effluents. Propene (Praxair, 50\% propene, 50\% argon), 1-hexene (Sigma-Aldrich, 99\% purity), toluene (Sigma-Aldrich, 99.5\% purity), $p$-xylene (Sigma-Aldrich, 99\% purity), and 2,6-di-tert-butylpyridine (Sigma-Aldrich, 97\% purity) were co-fed, without further purification, with dimethyl ether, in some cases as co-reactants. Gas flow rates were maintained using Brooks 
Instrument 5850S/SLA5850 series mass flow controllers. Liquids were fed through a $1.0 \mathrm{~mL}$ SGE syringe using a Cole Palmer EW-74900-00 syringe pump.

Reaction effluents were analyzed using an online gas chromatograph (Agilent 7890) equipped with a $50 \mathrm{~m} \times 320 \mu \mathrm{m} \times 0.52 \mu \mathrm{m}$ dimethylpolysiloxane J\&W HP-1 column connected to a flame ionization detector (FID). The product distributions shown in Section 3 include $\mathrm{C}_{8}{ }^{+}$ hydrocarbons that were not identified separately and are classified as "Others". The average hydrogen to carbon ratio $(\mathrm{H} / \mathrm{C})$ of the hydrocarbon species present in the "Others" fraction was calculated from the hydrogen and carbon content of known hydrocarbon species in the converted feed and the reaction effluent, and is reported with the data in some cases.

\section{Results and discussion}

\subsection{Structural and chemical characterization}

The diffusion length and the fraction of external Brønsted acid sites in SPP MFI and 3DOm-i MFI samples were estimated by Zhang et al. [37] and are reported in Table 1. The relevant diffusion length in the Conv MFI sample was estimated by Khare et al. [36] and is also reported in Table 1. The silicon to aluminum ratio $(\mathrm{Si} / \mathrm{Al})$ in the zeolite samples used in this study, as estimated from ICP-OES elemental analysis is also reported in Table 1.

\subsection{Catalytic reactions of DME on SPP MFI and 3DOm-i MFI}

\subsubsection{DME conversion on SPP MFI and 3DOm-i MFI}

Previously, we reported that ethene selectivity, for the reaction of DME on SPP MFI ( 1 $\mathrm{nm}$ diffusion length) at $623 \mathrm{~K}$ and 59\% net DME conversion, was 1.5\% (Table 2). [36] In comparison, ethene selectivity was $5.7 \%$ on 3DOm-i MFI ( $20 \mathrm{~nm}$ diffusion length) and $13.2 \%$ on a conventional MFI sample (Conv MFI, $\sim 250 \mathrm{~nm}$ diffusion length) at $623 \mathrm{~K}$ and $46-59 \%$ net 
DME conversion (Table 2). [36] This increase in ethene selectivity with increasing diffusion length was attributed to the enhanced propagation of the aromatics-based catalytic cycle. [36] Ethene selectivity on SPP MFI is low because MBs, once formed, exit the zeolite crystal without undergoing further dealkylation reactions due to the short diffusion length, resulting in the suppression of the aromatics-based catalytic cycle. As the diffusion length increases, the intracrystalline residence time of MBs increases, which enhances the propagation of the aromaticsbased catalytic cycle, and a concomitant increase in ethene selectivity is observed. Ilias et al. [16] showed that the ratio of the synthesis rates of ethene and the sum of 2-methyl-2-butene and 2-methylbutane (referred to as Ethene/2MBu) is a descriptor of the relative extent of propagation of the aromatics-based and olefins-based catalytic cycles in MFI. Enhanced propagation of the aromatics-based catalytic cycle with increasing diffusion length is reflected in Ethene/2MBu, which increased monotonically from 0.19 in SPP MFI to 1.9 in Conv MFI at $623 \mathrm{~K}$ (refer to Table 2). Low ethene selectivity on diffusion-free MFI samples (SPP MFI and 3DOm-i MFI) at $623 \mathrm{~K}$ suggests that MFI, in the absence of diffusion limitations and at $<100 \%$ conversion, is a poor ethene synthesis catalyst and that the aromatics-based catalytic cycle is intrinsically suppressed in the pores of MFI.

In this study, DME conversion was investigated at a higher reaction temperature (723 K), as higher temperatures are more relevant to ZSM-5 based industrial processes. [14, 28, 38] Table 2 shows the reaction conditions and product distribution for the reaction of DME on SPP MFI and 3DOm-i MFI at $723 \mathrm{~K}$. Reaction conditions and product distribution for DME conversion on a conventional MFI sample (Conv MFI) are also shown, for comparison. Similar to the observations at $623 \mathrm{~K}$, ethene selectivity at $723 \mathrm{~K}$ was lower on SPP MFI (1.1\%) compared to 
ethene selectivity observed on 3DOm-i MFI (2.8\%) or Conv MFI (3.1\%), at 47-60\% net DME conversion. We note, however, that ethene selectivity on all zeolite samples was lower at $723 \mathrm{~K}$ compared to ethene selectivity observed at $623 \mathrm{~K}$. Figure 1 shows the fractional change in product selectivity on SPP MFI, 3DOm-i MFI, and Conv MFI, as the reaction temperature was increased from $623 \mathrm{~K}$ to $723 \mathrm{~K}$ at DME iso-conversion conditions. The selectivity toward $\mathrm{C}_{2}$, MBs, and "Others" fraction decreased while $\mathrm{C}_{3}$ and $\mathrm{C}_{4}-\mathrm{C}_{7}$ hydrocarbon selectivity increased at higher temperatures. These observations suggest that the aromatic methylation/dealkylation cycle is further suppressed at higher temperatures. A possible reason for this further decrease in the propagation of the aromatics-based catalytic cycle is a decrease in the concentration of chain carriers of the aromatics-based catalytic cycle at $723 \mathrm{~K}$ compared to the concentration of chain carriers at $623 \mathrm{~K}$. At higher temperatures, we infer that higher olefins prefer to crack or desorb instead of cyclizing and undergoing hydrogen-transfer reactions to form MBs. [16] A decrease in the concentration of MBs inside the zeolite pores decreases the probability that MBs will undergo a dealkylation event to produce ethene and complete the catalytic cycle. These results suggest that the propagation of the aromatics-based catalytic cycle is intrinsically suppressed in the pores of MFI, especially at higher reaction temperatures, due to lower concentrations of MBs.

\subsubsection{Effects of external Brønsted acid sites in SPP MFI on DME conversion}

The crystallite size of SPP MFI is very small ( $\sim 1 \mathrm{~nm}$ diffusion length), which results in $\sim 29 \%$ of the total Brønsted acid sites being present on the external surface of the catalyst. [37] In comparison, a conventional MFI sample (Conv MFI) has 3\% external Brønsted acid sites. [37] The large fraction of external Brønsted acid sites in SPP MFI can affect the selectivity of DME 
conversion. Catalytic reactions of DME were therefore carried out on SPP MFI in the presence of 2,6-di-tert-butylpyridine (DTBP) to passivate the external acid sites. DTBP is a sterically large basic molecule with a kinetic diameter of $1.05 \mathrm{~nm}$. [39] The large kinetic diameter of DTBP prevents it from entering the pores of MFI and therefore, DTBP only interacts with acid sites present on the external surface and near the pore-mouth region of MFI. The Brønsted acid sites circumscribed within the zeolite pores are largely unaffected by DTBP titration. DME was reacted with $0.03-0.85 \mathrm{kPa}$ DTBP on SPP MFI at $723 \mathrm{~K}$. The catalyst, in the presence of DTBP co-feed, deactivated rapidly, especially at higher DTBP pressure (the details of catalyst deactivation are reported in Section S.1 of the Supplementary Information). All subsequent DTBP co-feed reactions were therefore carried out at the lowest partial pressure of DTBP $(\sim 0.03$ $\mathrm{kPa})$ and the results reported are at short times-on-stream $(\sim 5 \mathrm{~min})$. A possible explanation for the fast deactivation is the adsorption of DTBP on Brønsted acid sites near the pore-mouth, which can prevent bulkier molecules like MBs and other coke precursors from exiting the zeolite. Bleken et al. [40], in an experimental study, investigated the effects of catalyst deactivation on methanol conversion over H-ZSM-5 at $623 \mathrm{~K}$ and showed that the selectivity was largely independent of coke content in the catalyst. Along the same lines we report that product selectivity versus DME conversion for the case when DME conversion was varied by changing the DME space velocity $\left(7.8\right.$ and $\left.17 \mathrm{~mol} \mathrm{C}(\mathrm{mol} \mathrm{Al}-\mathrm{s})^{-1}\right)$ overlapped with the selectivity versus conversion trend noted when conversion varied due to deactivation of the catalyst bed for the nanocrystalline SPP MFI sample (Figure S.2 in the Supplementary Information). Therefore, the results reported for DTBP co-feed experiments, even though affected by coke deposition at short times-on-stream, are representative of stable MTH conversion selectivity on SPP MFI in 
the absence of external Brønsted acid sites (refer to Section S.1 of the Supplementary Information for a detailed discussion).

Reaction conditions and product distribution for the reaction of DME on SPP MFI at 723 $\mathrm{K}$ in the presence of $\sim 0.03 \mathrm{kPa}$ DTBP are reported in Table S.1 of the Supplementary Information. Reaction conditions and product distribution for the reaction of DME alone (without DTBP) on SPP MFI at iso-conversion conditions are also reported, for comparison. Figure 2 shows the effects of co-feeding DTBP, and therefore the effects of passivating external Brønsted acid sites, on the product selectivity for the reaction of DME on SPP MFI at $723 \mathrm{~K}$ and $42-43 \%$ net DME conversion. No significant change in product selectivity was observed in the presence of DTBP co-feed with the exception of MB selectivity, which decreased from $1.0 \%$ without DTBP to $0.6 \%$ with DTBP, and ethene selectivity, which increased marginally from $0.9 \%$ in the absence of DTBP to $1.1 \%$ in the presence of DTBP. A possible explanation for this anomaly is the adsorption of DTBP on acid sites close to the pore-mouth, which prevented bulkier molecules like MBs from exiting the crystal. This resulted in lower MBs selectivity in the effluent stream. Longer intra-crystalline residence time of MBs enhanced the propagation of the aromatics-based catalytic cycle and this resulted in higher selectivity towards ethene. These results suggest that the adsorption of DTBP on external acid sites increased the 'effective' diffusion length in SPP MFI. This increase however, is negligible as assessed from a comparison of the ethene selectivity and Ethene/2MBu for DME conversion on SPP with and without DTBP co-feed and 3DOm-i MFI reported in Table S.1. The diffusion length in 3DOm-i MFI ( 20 nm) is larger than the diffusion length in SPP MFI $(\sim 1 \mathrm{~nm})$ and as a result, ethene selectivity on 3DOm-i MFI (2.8\%) is $\sim 200 \%$ higher than the ethene selectivity observed on SPP MFI ( $0.9 \%)$. 
Ethene/2MBu on 3DOm-i MFI (0.36) is also significantly higher than Ethene/2MBu on SPP MFI (0.15). DTBP co-feed on SPP MFI results only in a marginal increase in ethene selectivity $(1.1 \%)$ and Ethene/2MBu $(0.16)$ compared to experiments done in absence of DTBP and implies that the increase in 'effective' diffusion length is insignificant and can be neglected in reference to assessing the effects of passivating external Brønsted acid sites in SPP MFI on the product selectivity of DME conversion.

Figure 2 shows that the observed selectivity is largely unaffected by the passivation of external acid sites therefore we conclude that the external Brønsted acid sites do not play a significant role in determining the selectivity of DME conversion. Kim and Ryoo also investigated the effects of external surface in MFI nanosheets ( $\sim 30 \%$ external acid sites) on MTH conversion and showed that when the external sites were poisoned by triphenylphosphine oxide, the catalytic cracking of 1,3,5-tri-iso-propylbenzene, a reaction that occurs only on the external surface, was completely suppressed. [41] Methanol conversion was, however, unaffected by triphenylphosphine oxide poisoning. [41]

\subsection{Effects of co-feeding olefins/methylbenzenes with DME}

\subsubsection{Effects of co-feeding olefins with DME on SPP MFI}

Table 3 shows the reaction conditions, feed composition, and product distribution, and Figure 3 shows ethene selectivity, $2 \mathrm{MBu}$ selectivity, and Ethene/2MBu, for the reaction of DME with 1-hexene or propene on SPP MFI at $723 \mathrm{~K}$. It can be observed that co-feeding propene or 1hexene with DME had no effect on the overall product selectivity. This suggests that the number of chain-carriers of the olefins-based catalytic cycle is already high or saturated inside the pores of MFI, consequently co-feeding propene/1-hexene did not significantly enhance the 
concentration of olefins. The propagation of the olefins-based catalytic cycle was therefore not enhanced by the presence of an olefin in the feed under the applied reaction conditions. This is also substantiated by the observation that Ethene/2MBu is unaffected by the presence of propene or 1-hexene thereby confirming that the olefins-based catalytic cycle was not selectively enhanced (refer to Figure 3). It is important to note that even under the conditions where the number of chain-carriers of the olefins-based catalytic cycle was saturated inside the pores of MFI, ethene selectivity was very low (1.1\%). The implication of this observation is that even if all ethene were being produced from the olefins-based catalytic cycle, the production of ethene from the olefin methylation/cracking cycle on a diffusion-free MFI sample at $<100 \%$ DME conversion, thereby representing the intrinsic mechanistic behavior of MTH catalysis on MFI, is insignificant under the applied reaction conditions.

\subsubsection{Effects of co-feeding methylbenzenes with DME on SPP MFI}

Table 3 shows the reaction conditions, feed composition, and product distribution, and Figure 3 shows ethene selectivity, $2 \mathrm{MBu}$ selectivity, and Ethene/2MBu, for the reaction of DME with toluene or $p$-xylene on SPP MFI at $723 \mathrm{~K}$. Ethene selectivity increased at least 2-fold when either toluene or $p$-xylene was co-fed with DME. The concentration of MBs in the reaction effluent also increased from $1.6 \%$ without any co-feed to $21.4 \%$ and $19.4 \%$ (the reported selectivity includes the unreacted co-feed) in the presence of toluene or $p$-xylene, respectively. The kinetic diameter of toluene and $p$-xylene $(0.585 \mathrm{~nm})[42,43]$ is comparable to the diameter of pore-openings in MFI $(\sim 0.55 \mathrm{~nm})[44,45]$ and these molecules can enter the pores of MFI. Co-feeding toluene or $p$-xylene therefore increases the concentration of MBs inside the zeolite pores. Higher concentration of MBs inside the zeolite pores increases the probability that some 
of these MBs will undergo a dealkylation event before exiting the crystal thereby enhancing the propagation of the aromatics-based catalytic cycle. Figure 3 shows that Ethene/2MBu increased from 0.15 with no co-feed to 0.42 and 0.45 when either toluene or $p$-xylene were co-fed with DME, respectively, confirming that the propagation of the aromatics-based catalytic cycle was enhanced relative to the olefins-based catalytic cycle in the presence of aromatic co-feed. These results suggest that the propagation of the aromatics-based catalytic cycle and its contribution towards ethene production is minimal (in the absence of aromatic co-feed) on SPP MFI at $723 \mathrm{~K}$ and $<100 \%$ conversion because the number of chain carriers of aromatics-based cycle inside the zeolite pores is low. Increasing the number of chain carriers of the aromatics-based catalytic cycle significantly enhanced the propagation of the aromatics-based catalytic cycle and results in higher ethene selectivity, even for a diffusion-free MFI sample.

\subsubsection{Effects of co-feeding 1,2,4-triMB with DME on SPP MFI}

DME was also reacted in the presence of 1,2,4-triMB on SPP MFI at $723 \mathrm{~K}$. Reaction conditions, feed composition, and product distribution, as well as ethene selectivity, $2 \mathrm{MBu}$ selectivity, and Ethene/2MBu, for this reaction are reported in Table 3 and Figure 3, respectively. Unlike toluene or $p$-xylene, co-feeding 1,2,4-triMB with DME did not increase ethene selectivity under similar reaction conditions. A possible reason for this observation may be associated with the kinetic diameters of these molecules. The kinetic diameter of 1,2,4-triMB $(0.680 \mathrm{~nm})$ is larger than the kinetic diameter of toluene or $p$-xylene $(0.585 \mathrm{~nm})$. [42, 43] The bulkier nature of 1,2,4-triMB prevents it from entering the pores of MFI. Co-feeding 1,2,4-triMB with DME, therefore, did not increase the concentration of MBs inside the zeolite pores and as a result, propagation of the aromatics-based catalytic cycle was not enhanced in the presence of $1,2,4-$ 
triMB co-feed. This is also reflected in Ethene $/ 2 \mathrm{MBu}$, which changed only marginally from 0.15 to 0.22 when 1,2,4-triMB was co-reacted with DME (in comparison to a $\sim 3$-fold increase in the presence of toluene or $p$-xylene co-feed).

Table S.5 of the Supplementary Information shows the normalized molar flow rates of MBs in the reaction effluent, for the catalytic reaction of DME with 1,2,4-triMB co-feed, on SPP MFI at $723 \mathrm{~K}$. Normalized MB flow rates for the reaction of DME alone on SPP MFI at $723 \mathrm{~K}$ are also reported for comparison. It can be noted that even though 1,2,4-triMB did not enter the pores of MFI, methylation of 1,2,4-triMB still occurred as the concentration of more substituted MBs (tetraMBs, pentaMB, or hexaMB) in the effluent stream increased significantly in comparison to the experiment in which no 1,2,4-triMB was co-fed. We postulate, based on these observations, that methylation of MBs to higher MB homologues occurs on the external surface, however, aromatic dealkylation reactions, which are precursors to ethene, require confinement within zeolite micropores as no increase in ethene selectivity or Ethene/2MBu was observed when 1,2,4-triMB was co-fed.

\subsubsection{Effects of external Brønsted acid sites in SPP MFI on MB methylation}

We postulated in Section 3.3.3 that methylation of MBs occurs on the external surface of MFI. DME was reacted with toluene, $p$-xylene, or 1,2,4-triMB, in the presence of 2,6-di-tertbutylpridine (DTBP) to confirm this hypothesis. Reaction conditions and product distribution (including distribution of MBs and normalized molar flow rates of MBs in the reaction effluent) for the catalytic reaction of DME with toluene, $p$-xylene, or 1,2,4-triMB in the presence/absence of DTBP on SPP MFI at $723 \mathrm{~K}$ are reported and discussed in detail in Section S.3 of the Supplementary Information. No significant change in the overall product selectivity was 
observed after the external Brønsted acid sites were passivated by DTBP suggesting that external surface does not play a major role in determining the product distribution of DME conversion (refer to Table S.3 and Figure S.3 in Section S.3 of the Supplementary Information). It was observed however, that the normalized molar flow rate of higher MBs in the reaction effluent in the presence of DTBP co-feed was lower in comparison to the experiment in which no DTBP was co-fed (refer to Table S.5 of the Supplementary Information). This implies that MB methylation was suppressed in the presence of DTBP, suggesting that methylation of MBs to more substituted MB homologues occurred, at least to some extent, on the external surface of SPP MFI. Figure S.4 in the Supplementary Information shows the fraction of toluene, $p$-xylene, or 1,2,4-triMB, that underwent methylation in the presence/absence of DTBP. No significant change in toluene methylation was observed in the presence of DTBP. Methylation of $p$-xylene and 1,2,4-triMB was, however, suppressed in the presence of DTBP. In addition, methylation of 1,2,4-triMB was suppressed to a greater extent than $p$-xylene. These observations support our postulate that the methylation of highly substituted MBs, which cannot enter the pores of MFI, occurs on the external surface and is suppressed in the absence of external Brønsted acid sites.

\subsubsection{Effects of co-feeding methylbenzenes/olefins with DME on 3DOm-i MFI}

Table 4 shows the reaction conditions, feed composition, and product distribution, and Figure 4 shows ethene selectivity, $2 \mathrm{MBu}$ selectivity, and Ethene/2MBu, for the reaction of DME in the presence/absence of aromatic or olefin co-feed on 3DOm-i MFI at $723 \mathrm{~K}$. Similar to the observations on SPP MFI, co-feeding propene or 1-hexene with DME had no effect on ethene selectivity and Ethene/2MBu, suggesting that the concentration of olefins inside the pores of 3DOm-i MFI is saturated and the olefins-based catalytic cycle was not enhanced in the presence 
of an olefin co-feed. Co-feeding toluene or $p$-xylene with DME, on the other hand, resulted in a $\sim 3$-fold increase in ethene selectivity as well as a $\sim 4$-fold increase in Ethene/2MBu, suggesting that, similar to what was noted for the SPP MFI sample, the relative extent of propagation of the aromatics-based catalytic cycle was enhanced in the presence of aromatic co-feed.

\subsubsection{Effects of co-feeding methylbenzenes/olefins with DME on Conv MFI}

The effects of co-feeding propene or toluene with DME on a conventional MFI zeolite (Conv MFI) at $723 \mathrm{~K}$ are reported and discussed in Section S.2 of the Supplementary Information. It was noted that co-feeding propene with DME resulted in a decrease in ethene selectivity as well as Ethene/2MBu (refer to Table S.2 in the Supplementary Information). These results are different from those obtained on SPP MFI or 3DOm-i MFI where co-feeding propene or 1-hexene did not change ethene selectivity or Ethene/2MBu. Co-feeding toluene with DME on Conv MFI, on the other hand, had similar effects as those obtained on diffusion-free MFI samples, and resulted in an increase in ethene selectivity and Ethene/2MBu (refer to Table S.2 in the Supplementary Information).

We postulated that the concentration of olefins is high inside the pores of SPP and 3DOm-i MFI and therefore, co-feeding olefins does not significantly enhance the olefins-based catalytic cycle. On the other hand, as the intrinsic concentration of MBs inside the zeolite pores at $723 \mathrm{~K}$ is low, any change in $\mathrm{MB}$ concentration significantly affects the propagation of the aromatics-based catalytic cycle. Co-feeding propene with DME increased the concentration of olefins inside the zeolite pores, which lowered the relative concentration of MBs inside the pores thereby indirectly suppressing the aromatics-based catalytic cycle. This effect is more prominent in the conventional MFI sample where the number of chain carriers of the aromatics-based cycle 
is higher and the aromatics- methylation/cracking cycle is contributing significantly towards the production of ethene. In the diffusion-free MFI sample, however, this effect is insignificant as the concentration of methylbenzenes inside the pores is intrinsically very low and was not suppressed further in the presence of olefin co-feed (see discussion in Section S.2 of the Supplementary Information).

\subsection{Effects of DME space-velocity on MTH conversion}

Brønsted acid sites in zeolites interact with DME or methanol to form surface methyls. $[11,13]$ Reactions of these surface methyls with unsaturated molecules like olefins or aromatics, that are co-catalysts for MTH conversion, result in the complex hydrocarbon distribution observed in the effluent. [7-13] The presence or absence of these methyls can alter the chemistry that occurs inside the zeolite pores. Conversion of DME/methanol increases as DME spacevelocity decreases and eventually reaches $100 \%$ when all $\mathrm{DME} /$ methanol is consumed. If the space-velocity is further reduced, the catalyst bed can be modeled to comprise two distinct stages: the first stage performs MTH chemistry in the presence of surface methyls; the second stage begins after all DME/methanol is consumed and, as surface methyls do not exist in this stage, only chemistry that can propagate in their absence occurs in this stage of the catalyst bed. The dual-staged catalytic bed discussed here is analogous to the depiction of time-evolution of a catalyst bed as a "cigar-burn" by Haw et al. [46] As the space-velocity of DME decreases, the fraction of bed acting as the 'first-stage' decreases while the fraction of bed acting as the 'second-stage' increases. Figure 5 shows the fraction of catalyst bed performing MTH conversion chemistry in the presence of DME/methanol. It can be observed that the fraction of catalyst bed acting as the 'first-stage' decreases as DME space velocity decreases (or DME 
space-time increases) and at the lowest space-velocity investigated in this study $(0.31 \mathrm{~mol} \mathrm{C}$ $[\mathrm{mol} \mathrm{Al}-\mathrm{s}]^{-1}$ ), only $12.5 \%$ of the catalyst bed is performing MTH chemistry and a majority of the catalyst bed is acting as the 'second-stage'.

DME was reacted on SPP MFI at $723 \mathrm{~K}, \sim 60 \mathrm{kPa}$ DME pressure, and at DME spacevelocity varying between 0.3 and $17 \mathrm{~mol} \mathrm{C}$ (mol Al-s) ${ }^{-1}$. Figure 5 shows the effects of DME space-velocity on net DME conversion. The results consist of three separate experiments. In each experiment, DME space-velocity was decreased sequentially to obtain 7-8 data-points (with replicates in some cases) at a different DME space-velocity. The catalyst was not regenerated between each data-point and therefore, the data-points acquired later were affected to a small extent by catalyst deactivation. The catalyst was regenerated in $1.67 \mathrm{~cm}^{3} \mathrm{~s}^{-1}$ dry air (Minneapolis Oxygen, $20-21 \% \mathrm{O}_{2},<10 \mathrm{ppm} \mathrm{H}_{2} \mathrm{O}$ ) at $823 \mathrm{~K}$ for $4 \mathrm{~h}$ between the experiments and the initial data-point in each experiment, as a result, is not affected by catalyst deactivation. DME conversions observed in some cases are therefore slightly different at similar DME spacevelocity (but in different experiments) due to deactivation of the catalyst bed.

We have segregated the data into two separate sets of data-points to understand the effects of DME space-velocity on product distribution. The first set comprises data where net DME conversion was less than $100 \%$. These data correspond to DME conversion occurring on a single-staged catalytic bed. The second set of data comprises data where net DME conversion was $100 \%$ and no DME/methanol was observed in the effluent. These data correspond to DME conversion occurring on a two-staged catalytic bed. Data in the second set are reported as product selectivity versus DME space-time (in mol Al $[\mathrm{mol} \mathrm{C} / \mathrm{s}]^{-1}$ ) and are shown in Figure 6 (b). Data in the first set, however, are presented as product selectivity versus DME conversion 
instead of DME space-time to account for catalyst deactivation and are shown in Figure 6 (a). Together, the two data-sets represent the effects of DME space-velocity (or DME space-time) on selectivity toward $\mathrm{C}_{2}, \mathrm{C}_{3}, \mathrm{C}_{4}-\mathrm{C}_{7}$, methylbenzenes, and "Others" fraction, for the reaction of DME on SPP MFI at $723 \mathrm{~K}$ and DME space-velocity varying between 0.3 and 17 mol C (mol Al-s) ${ }^{-1}$.

It can be seen from Figure 6 (a) that as DME conversion increases (or as DME spacevelocity decreases), selectivity toward $\mathrm{C}_{4}-\mathrm{C}_{7}$ and "Others" fraction decreases while $\mathrm{C}_{2}, \mathrm{C}_{3}$, and MB selectivity increases. These observations suggest that with increasing DME conversion, secondary reactions become more prominent; higher olefins either crack to form lighter olefins or undergo hydrogen-transfer and cyclization reactions to form $\mathrm{MBs}$, which in turn can also produce light olefins via aromatic dealkylation reactions. We note that the selectivity towards the "Others" fraction continued to decrease and $\mathrm{C}_{2}$ and $\mathrm{MBs}$ selectivity continued to increase with a decrease in DME space-velocity, even after 100\% DME conversion was achieved (refer to Figure 6(b)), however, only a minor change in the selectivity of $\mathrm{C}_{3}$ and higher olefins was observed as DME/methanol space-velocity was reduced. It must also be noted that even though the overall $\mathrm{C}_{4}-\mathrm{C}_{7}$ selectivity seems largely unaffected by the variations in DME space-velocity, the selectivity towards individual $\mathrm{C}_{4^{-}}, \mathrm{C}_{5^{-}}, \mathrm{C}_{6^{-}}$, and $\mathrm{C}_{7}$-aliphatic hydrocarbons changed slightly and is reported in Figure S.5 of the Supplementary Information. $\mathrm{C}_{4}$ selectivity increases while the selectivity toward $\mathrm{C}_{5}+$ aliphatic hydrocarbons (mostly olefins) decreases with a decrease in DME/methanol space-velocity. These observations suggest that oligomerization/ $\beta$-scission olefin inter-conversion reactions are occurring in the 'second-stage' of the catalyst bed in the absence of surface methyls. As the selectivity towards $\mathrm{C}_{5}+$ aliphatic hydrocarbons decreases with decreasing space-velocity, this suggests that the rate of formation of these olefins is lower than 
their rate of consumption, possibly because higher olefins can cyclize and undergo hydrogentransfer reactions to form MBs and these reactions act as a carbon sink for these hydrocarbons.

There are two possible explanations for the observed increase in ethene selectivity: (i) higher olefins crack to form ethene, and/or (ii) MBs dealkylate in the absence of surface methyls (but in the presence of other olefins) to form ethene. Both these reaction events can explain the observed increase in ethene selectivity with decreasing DME space-velocity. Below, we discuss experimental evidence that precludes scenario (ii) above.

\subsection{Catalytic reactions of propene on SPP MFI}

\subsubsection{Catalytic reactions of propene only on SPP MFI at $723 \mathrm{~K}$}

Propene was reacted on SPP MFI at $723 \mathrm{~K}$ and $\sim 115 \mathrm{kPa}$ total feed pressure to emulate the second stage of the catalyst bed and investigate olefin inter-conversion reactions in the absence of DME/methanol. Propene space-velocity was varied from 0.4 to $3.0 \mathrm{~mol} \mathrm{C}$ (mol Al-s)

${ }^{1}$. The product distribution for this reaction as a function of propene space-velocity is shown in Figure S.6 of the Supplementary Information. Higher olefins were detected in the reaction effluent implying that olefin oligomerization and cracking occurred in the 'second-stage' of the catalyst bed in the absence of DME/methanol. The presence of MBs in the reaction effluent suggests that higher olefins can also undergo cyclization and hydrogen-transfer reactions in the absence of DME/methanol to form MBs. A significant amount of ethene was also observed in the reaction effluent ( $\sim 7 \%$ carbon selectivity, see Figure S.6(b)) . As briefly discussed in Section 3.4, there are two possible routes for the formation of ethene: (i) cracking of higher olefins, and/or (ii) dealkylation of MBs, in the absence of DME/methanol. A mixture of MBs was co-fed 
with propene to assess whether aromatic methylation/dealkylation sequences propagate in absence of DME/methanol.

\subsubsection{Catalytic reactions of propene with methylbenzenes on SPP MFI at $723 \mathrm{~K}$}

Propene was reacted with a mixture of $38 \mathrm{~mol} \%$ toluene, $33 \mathrm{~mol} \%$ p-xylene, and 29 mol\% 1,2,4-triMB on SPP MFI at $723 \mathrm{~K}$ and $\sim 115 \mathrm{kPa}$ total feed pressure. Table 5 shows the feed composition and product distribution for this reaction. Reaction conditions and product distribution for the reaction of propene alone on SPP MFI at $723 \mathrm{~K}$ and similar carbon spacevelocity are also reported in Table 5 for comparison. Addition of MBs to the feed resulted in a 9-fold increase in the concentration of MBs in the effluent stream and it is likely that the concentration of MBs inside the pores was also enhanced. If ethene were to form via MB dealkylation reactions in the absence of a methylating agent, a significant increase in the concentration of MBs inside the zeolite pores must result in higher ethene selectivity. It was observed however, that co-feeding MBs with propene did not change ethene selectivity or the overall product distribution, when estimated after excluding MBs from the calculations (also shown in Table 5). These observations suggest that MBs did not dealkylate in the absence of $\mathrm{DME} /$ methanol. Ethene observed in the reaction effluent therefore, is not a significant product of aromatic dealkylation reactions. The aromatics-based catalytic cycle is shut down in the absence of DME/methanol as MBs, even though being formed from higher olefins, cannot undergo dealkylation in the absence of DME/methanol to complete the catalytic cycle.

\subsubsection{Catalytic reactions of propene with ethene on SPP MFI at $723 \mathrm{~K}$}

Figure 6 (b) shows that ethene selectivity increased from $3.1 \%$ to $7.4 \%$, after complete DME conversion was achieved, as DME space-velocity was varied from 0.3 to $2.5 \mathrm{~mol} \mathrm{C}$ (mol 
$\mathrm{Al}-\mathrm{s})^{-1}$. The change in selectivity toward $\mathrm{C}_{3^{-}}$to $\mathrm{C}_{7}$-aliphatic hydrocarbon with DME spacevelocity is reported in Section S.4 of the Supplementary Information. It can be seen that the selectivity toward $\mathrm{C}_{3}+$ aliphatics (mostly olefins) was not affected to the same extent as ethene selectivity. Ethene selectivity increased by $\sim 130 \%$ in comparison with a $<23 \%$ change in the selectivity toward $\mathrm{C}_{3}+$ aliphatics. The relatively small change in selectivity towards $\mathrm{C}_{3}-$ to $\mathrm{C}_{7}-$ aliphatic hydrocarbons can be attributed to olefin inter-conversion reactions which render the rate of formation of $\mathrm{C}_{3}+$ olefins nearly equal to the rate of consumption of these olefins by $\mathrm{C}-\mathrm{C}$ bond scission. The significantly larger change in ethene selectivity suggests that the rate of formation of ethene from olefin cracking is higher than the rate of consumption of ethene via oligomerization reactions, under the employed reaction conditions. A possible reason for the continual increase in ethene selectivity with decreasing DME space-velocity is that ethene does not participate in olefin inter-conversion, at least to the same extent as $\mathrm{C}_{3}+$ olefins, possibly due to its lower reactivity. Hill et al. [47] showed that the ethene methylation is at least an order of magnitude slower than methylation of $\mathrm{C}_{3}+$ olefins on MFI.

Propene was reacted on SPP MFI at $723 \mathrm{~K}$ in the presence of ethene to confirm our hypothesis that ethene does not participate in olefin inter-conversion reactions, to a similar extent as $\mathrm{C}_{3}+$ olefins, due to its lower reactivity. Table 6 shows the reaction conditions and product selectivity for the reaction of propene in the presence of ethene on SPP MFI at $723 \mathrm{~K}$. Product selectivity for the reaction of propene alone on SPP MFI at $723 \mathrm{~K}$ and similar propene spacevelocity is also reported in Table 6 for comparison. In the case when $6.9 \%$ ethene was co-reacted with propene, ethene selectivity observed in the effluent was slightly higher $(7.8 \%)$ than ethene concentration in the feed suggesting that the net rate of formation of ethene under these reaction 
conditions was positive. In the case when $11.2 \%$ ethene was co-reacted with propene, however, the concentration of ethene in the effluent was slightly lower $(10.6 \%)$ than that in the feed suggesting that as the concentration of ethene increases inside the zeolite pores, the rate of consumption of ethene via oligomerization surpasses the rate of ethene production via olefin cracking reactions, and the net rate of ethene formation approaches zero and eventually becomes negative as ethene concentration in the effluent increases.

Early work by Haag et al. [48] acknowledges MTH conversion on MFI as a diffusion disguised process, and our recent report [36] suggests that the selectivity of DME conversion is a strong function of diffusion length in MFI. Investigation of MTH conversion on diffusion-free MFI samples, in this study, therefore provides an intrinsic mechanistic basis of MTH conversion on MFI type zeolites in the absence of any diffusion limitations. The olefins-based hydrocarbon pool is saturated inside the pores of MFI at $<100 \%$ conversion, but its intrinsic contribution towards the formation of ethene is minimal. The aromatics-based catalytic cycle, on the other hand, is a significant contributor to ethene formation; however, it is suppressed in the pores of diffusion-free MFI samples due to the low number of chain carriers of the aromatics-based cycle and the short diffusion length. MFI therefore, is intrinsically a poor ethene synthesis catalyst at $723 \mathrm{~K}$ and $<100 \%$ conversion. Under industrially relevant reaction conditions i.e., high temperature $(723 \mathrm{~K})$ and low DME space-velocity $\left(\leq 2.5 \mathrm{~mol} \mathrm{C}[\mathrm{mol} \mathrm{Al}-\mathrm{s}]^{-1}\right)$, that result in complete DME conversion, the catalyst bed comprises two catalytic stages: the first stage performs MTH chemistry with concurrent propagation of aromatic/olefin methylation and cracking cycles while the second stage, which begins after 100\% DME conversion is achieved, mostly performs olefin inter-conversion. 
Two critical mechanistic inferences can be deduced from this study: (i) ethene is primarily formed under MTH conditions $(<100 \%$ conversion) as a consequence of diffusion limitations; and (ii) reaction conditions that result in complete DME conversion and therefore the absence of surface methyl groups, result in aromatic methylation/dealkylation cycle being absent in the majority of the bed and the downstream chemistry primarily constitutes olefin interconversion. Mechanistic consequences as to the predominance of the aromatics- or the olefinsbased catalytic cycle and the identity and reactivity of specific hydrocarbon pool components therefore cannot be rigorously inferred under experimental conditions that result in complete DME/methanol conversion.

\section{Conclusions}

SPP MFI ( 1 nm diffusion length) exhibited low ethene selectivity (1.1\%), for the reaction of DME at $723 \mathrm{~K}$ and $<100 \%$ conversion suggesting that MFI, in the absence of diffusion limitations and at industrially relevant reaction temperatures $(723 \mathrm{~K})$, is a poor ethene synthesis catalyst. Low ethene selectivity under these reaction conditions is attributed to the near absence of the aromatics-based methylation/C-C bond scission catalytic cycle inside the pores of SPP MFI. 3DOm-i MFI ( $\sim 20 \mathrm{~nm}$ diffusion length) and a conventional MFI sample ( $\sim 250 \mathrm{~nm}$ diffusion length), in comparison exhibit higher ethene selectivity ( $2.8 \%$ and $3.1 \%$, respectively) under similar reaction conditions.

Co-feeding propene or 1-hexene with DME on SPP MFI and 3DOm-i MFI at $723 \mathrm{~K}$ did not affect the overall product selectivity or Ethene $/ 2 \mathrm{MBu}$, suggesting that the olefins-based hydrocarbon pool is saturated in the pores of diffusion-free MFI samples. The selectivity towards 
ethene was low ( $1.1 \%$ on SPP MFI and $2.8 \%$ on 3DOm-i MFI) even under the conditions where the olefins-based hydrocarbon pool is saturated implying that the contribution of the olefinsbased methylation/cracking cycle towards ethene production is minimal at $723 \mathrm{~K}$ and $<100 \%$ conversion. Co-feeding toluene or $p$-xylene with DME on SPP MFI and 3DOm-i MFI at $723 \mathrm{~K}$, on the other hand, enhanced the concentration of MBs inside the zeolite pores and a corresponding increase in ethene selectivity was observed suggesting that the low ethene production in SPP MFI at $723 \mathrm{~K}$ and $<100 \%$ conversion is because the number of chain carriers of the aromatics-based catalytic cycle, typically MBs, inside the zeolite pores is low.

The presence of a large fraction of external Brønsted acid sites in SPP MFI ( 29\%) does not affect the overall product selectivity of MTH conversion at $723 \mathrm{~K}$. The methylation of MBs to higher MB homologues, which occurs on the external surface, is suppressed by passivation of the external acid sites by DTBP titration. Aromatic dealkylation reactions, which form ethene, however, occur only within the confinement of zeolite micropores and are therefore not affected by the passivation of external Brønsted acid sites.

At high temperature $(723 \mathrm{~K})$ and low DME space-velocity $\left(\leq 2.5 \mathrm{~mol} \mathrm{C}[\mathrm{mol} \mathrm{Al}-\mathrm{s}]^{-1}\right)$, conditions more relevant to ZSM-5 based industrial processes, the catalyst bed comprises of two catalytic stages: the first stage performs MTH chemistry in the presence of DME/methanol; the second stage performs chemistry that can occur in the absence of a methylating agent. The aromatics-based catalytic cycle ceases to exist in the second stage of the catalytic bed, as MBs cannot undergo dealkylation reactions in the absence of DME/methanol and the dominant pathway to ethene formation under these reaction conditions is, therefore, olefin interconversion. 


\section{Acknowledgements}

The authors acknowledge financial support from The Dow Chemical Company and the National Science Foundation (CBET 1055846). The authors also acknowledge Ms. Dandan Xu, University of Minnesota, for the synthesis of SPP MFI zeolite sample and Prof. Dongxia Liu, University of Maryland, for the synthesis of 3DOm-i MFI zeolite sample. The authors also acknowledge Mr. Kyle Weideman, University of Minnesota, for help with the experimental setup. 


\section{References}

[1] S. Kolboe, Acta Chem. Scand. Ser. A 40 (1986) 711.

[2] S. Kolboe, Stud. Surf. Sci. Catal. 36 (1988) 189.

[3] I.M. Dahl, S. Kolboe, Catal. Lett. 20 (1993) 329.

[4] I.M. Dahl, S. Kolboe, J. Catal. 149 (1994) 458.

[5] S. Kolboe, I.M. Dahl, Stud. Surf. Sci. Catal. 94 (1995) 427.

[6] I.M. Dahl, S. Kolboe, J. Catal. 161 (1996) 304.

[7] R.M. Dessau, R.B. LaPierre, J. Catal. 78 (1982) 136.

[8] R.M. Dessau, J. Catal. 99 (1986) 111.

[9] W. Song, J.F. Haw, J.B. Nicholas, C.S. Heneghan, J. Am. Chem. Soc. 122 (2000) 10726.

[10] J.F. Haw, Phys. Chem. Chem. Phys. 4 (2002) 5431.

[11] J.F. Haw, W. Song, D.M. Marcus, J.B. Nicholas, Acc. Chem. Res. 36 (2003) 317.

[12] U. Olsbye, M. Bjørgen, S. Svelle, K.P. Lillerud, S. Kolboe, Catal. Today 106 (2005) 108.

[13] S. Ilias, A. Bhan, ACS Catal. 3 (2013) 18.

[14] U. Olsbye, S. Svelle, M. Bjørgen, P. Beato, T.V.W. Janssens, F. Joensen, S. Bordiga, K.P. Lillerud, Angew. Chem. Int. Ed. 51 (2012) 5810.

[15] S. Ilias, A. Bhan, J. Catal. 290 (2012) 186.

[16] S. Ilias, R. Khare, A. Malek, A. Bhan, J. Catal. 303 (2013) 135.

[17] T. Mole, J.A. Whiteside, D. Seddon, J. Catal. 82 (1983) 261.

[18] M. Bjørgen, U. Olsbye, D. Petersen, S. Kolboe, J. Catal. 221 (2004) 1.

[19] Ø Mikkelsen, P.O. Rønning, S. Kolboe, Micro. Meso. Mater. 40 (2000) 95.

[20] S. Svelle, F. Joensen, J. Nerlov, U. Olsbye, K.P. Lillerud, S. Kolboe, M. Bjørgen, J. Am. Chem. Soc. 128 (2006) 14770. 
[21] M. Bjørgen, S. Svelle, F. Joensen, J. Nerlov, S. Kolboe, F. Bonino, L. Palumbo, S. Bordiga, U. Olsbye, J. Catal. 249 (2007) 195.

[22] M. Bjørgen, F. Joensen, K.P. Lillerud, U. Olsbye, S. Svelle, Catal. Today 142 (2009) 90.

[23] J. Abbot, B.W. Wojciechowski, Canad. J. Chem. Eng. 63 (1985) 451.

[24] J. Abbot, B.W. Wojciechowski, Canad. J. Chem. Eng. 63 (1985) 462.

[25] S. Ilias, A. Bhan, J. Catal. 311 (2014) 6.

[26] T. Mole, J. Catal. 84 (1983) 423.

[27] C. Chen, S. Rangarajan, I.M. Hill, A. Bhan, ACS Catal. 4 (2014) 2319.

[28] X. Sun, S. Mueller, Y. Liu, H. Shi, G.L. Haller, M. Sanchez-Sanchez, A.C. van Veen, J.A. Lercher, J. Catal. 317 (2014) 185.

[29] X. Sun, S. Mueller, H. Shi, G.L. Haller, M. Sanchez-Sanchez, A.C. van Veen, J.A. Lercher, J. Catal. 314 (2014) 21.

[30] C.D. Chang, A.J. Silvestri, J. Catal. 47 (1977) 249.

[31] C.D. Chang, C.T. Chu, R.F. Socha, J. Catal. 86 (1984) 289.

[32] M. Sugimoto, H. Katsuno, K. Takatsu, N. Kawata, Zeolites 7 (1987) 503.

[33] A.A. Rownaghi, F. Rezaei, J. Hedlund, Catal. Commun. 14 (2011) 37.

[34] A.A. Rownaghi, J. Hedlund, Ind. Eng. Chem. Res. 50 (2011) 11872.

[35] B.L. Bleken, D.S. Wragg, B. Arstad, A.E. Gunnæs, J. Mouzon, S. Helveg, L.F. Lundegaard, P. Beato, S. Bordiga, U. Olsbye, S. Svelle, K.P. Lillerud, Top. in Catal. 56 (2013) 558.

[36] R. Khare, D. Millar, A. Bhan, J. Catal. 321 (2015) 23.

[37] X. Zhang, D. Liu, D. Xu, S. Asahina, K.A. Cychosz, K.V. Agrawal, Y. Al Wahedi, A. Bhan, S. Al Hashimi, O. Terasaki, M. Thommes, M. Tsapatsis, Science 336 (2012) 1684.

[38] H. Koempel, W. Liebner, Stud. Surf. Sci. Catal. 167 (2007) 261.

[39] S. Zheng, H.R. Heydenrych, A. Jentys, J.A. Lercher, J. Phys. Chem. B 106 (2002) 9552.

[40] F.L. Bleken, T.V.W. Janssens, S. Svelle, U. Olsbye, Micro. Meso. Mater. 164 (2012) 190. 
[41] W. Kim, R. Ryoo, Catal. Lett. 144 (2014) 1164.

[42] C.D. Baertsch, H.H. Funke, J.L. Falconer, R.D. Noble, J. Phys. Chem. 100 (1996) 7676.

[43] J. Kärger, D.M. Ruthven, Diffusion in Zeolites and Other Microporous Solids, John Wiley, New York, 1992, p. 605.

[44] G.T. Kokotailo, S.L. Lawton, D.H. Olson, W.M. Meier, Nature 272 (1978) 437.

[45] D.H. Olson, G.T. Kokotailo, S.L. Lawton, W.M. Meier, J. Phys. Chem. 85 (1981) 2238.

[46] J.F. Haw, D.M. Marcus, Top. Catal. 34 (2005) 41.

[47] I.M. Hill, S. Al Hashimi, A. Bhan, J. Catal. 285 (2012) 115.

[48] W.O. Haag, R.M. Lago, P.G. Rodewald, J. Mol. Catal. 17 (1982) 161. 


\section{Tables and captions}

Table 1. Diffusion length, fraction of external Brønsted acid sites $\left(\mathrm{f}_{\mathrm{B}, \text { ext }}\right)$, and silicon to aluminum ratio ( $\left.\mathrm{Si} / \mathrm{Al}\right)$, in the zeolite samples used in this study.

\begin{tabular}{lllc}
\hline Zeolite sample & \multicolumn{1}{c}{$\begin{array}{c}\text { Diffusion length } \\
(\mathbf{n m})\end{array}$} & \multicolumn{1}{c}{$\begin{array}{c}\text { Fraction of external Brønsted acid sites }^{\mathbf{a}} \\
\mathbf{f}_{\mathbf{B}, \boldsymbol{e x t}}\end{array}$} & $\mathbf{S i}_{\mathbf{A l}} \mathbf{A l}^{\mathbf{b}}$ \\
\hline SPP MFI & $1^{\mathrm{c}}$ & 0.29 & 84 \\
3DOm-i MFI & $20^{\mathrm{c}}$ & 0.14 & 72 \\
Conv MFI & $250^{\mathrm{d}}$ & 0.03 & 43 \\
\hline
\end{tabular}

\footnotetext{
${ }^{a}$ Ratio of the number of Brønsted acid sites as determined by 2,6-di-tert-butylpyridine titration and the number of Brønsted acid sites as determined by dimethyl ether titration (reference [37]).

${ }^{\mathrm{b}}$ Estimated from ICP-OES elemental analysis, performed by Galbraith Laboratories, Inc.

${ }^{\mathrm{c}}$ Estimated by Zhang et al. in reference [37].

${ }^{\mathrm{d}}$ Estimated by Khare et al. in reference [36].
} 
Table 2. Reaction conditions, net DME conversion, and product distribution, for the catalytic reaction of DME on SPP MFI, 3DOm-i MFI, and Conv MFI samples, at $623-723 \mathrm{~K}$, total feed pressure $\sim 120 \mathrm{kPa}$, and $20 \mathrm{~min}$ time-on-stream. Methanol was considered as a reactant in the calculation of net DME conversion.

\begin{tabular}{|c|c|c|c|c|c|c|}
\hline \multirow{2}{*}{$\begin{array}{r}\text { Zeolite } \\
\text { Reaction temperature }(\mathrm{K})\end{array}$} & \multicolumn{2}{|c|}{ SPP MFI } & \multicolumn{2}{|c|}{ 3DOm-i MFI } & \multicolumn{2}{|c|}{ Conv MFI } \\
\hline & $623^{a}$ & 723 & $623^{\mathrm{a}}$ & 723 & $623^{a}$ & 723 \\
\hline Carbon space velocity (mol C [mol Al-s] $]^{-1}$ ) & 1.8 & 9.7 & 2.2 & 11 & 3.2 & 40 \\
\hline DME partial pressure $(\mathrm{kPa})$ & 66 & 63 & 64 & 62 & 62 & 73 \\
\hline Net DME conversion $(\%)$ & 59 & 47 & 57 & 57 & 46 & 60 \\
\hline \multicolumn{7}{|c|}{ Product distribution (in \%, on a carbon basis): } \\
\hline $\mathrm{C}_{2}$ (Ethene) & $1.6(1.5)$ & $1.1(1.1)$ & $5.7(5.7)$ & $2.8(2.8)$ & $13.2(13.2)$ & $3.1(3.1)$ \\
\hline $\mathrm{C}_{3}$ (Propene) & $21.0(20.5)$ & $26.6(26.2)$ & $21.6(21.0)$ & $28.7(28.0)$ & $21.0(20.0)$ & $30.3(29.7)$ \\
\hline $\mathrm{C}_{4}-\mathrm{C}_{7}$ & 54.4 & 60.4 & 50.4 & 57.7 & 43.3 & 58.0 \\
\hline Methylbenzenes & 2.1 & 1.5 & 5.9 & 2.8 & 7.4 & 2.1 \\
\hline Others $^{b}$ & 21.0 & 10.4 & 16.4 & 8.0 & 15.1 & 6.5 \\
\hline Ethene $/ 2 \mathrm{MBu}^{\mathrm{c}}$ & 0.19 & 0.15 & 0.70 & 0.36 & 1.88 & 0.41 \\
\hline $\mathrm{H} / \mathrm{C}$ in "Others"d & 1.76 & 1.81 & 1.78 & 1.71 & 1.82 & 1.76 \\
\hline
\end{tabular}

${ }^{a}$ Data at $623 \mathrm{~K}$ are also reported in reference [36] by the authors.

$\mathrm{b}$ "Others" fraction includes $\mathrm{C}_{8}+$ hydrocarbons, except polymethylbenzenes.

${ }^{c}$ Ratio of the synthesis rates of ethene and 2-methylbutane +2 -methyl-2-butene.

d The hydrogen to carbon ratio $(\mathrm{H} / \mathrm{C})$ in "Others" fraction was calculated based on the difference in carbon and hydrogen content of known hydrocarbon species in the reaction effluent and the converted feed. 
Table 3. Reaction conditions, feed composition, and detailed product distribution, for the reaction of DME with olefin/aromatic cofeeds on SPP MFI at $723 \mathrm{~K}$, total feed pressure $\sim 120 \mathrm{kPa}$, and 20 min time-on-stream. Methanol was considered as a reactant in the calculation of net carbon conversion.

\begin{tabular}{|c|c|c|c|c|c|c|}
\hline Co-feed & 1-Hexene & Propene & None & Toluene & $p$-Xylene & 1,2,4-triMB \\
\hline Carbon space-velocity (mol C [mol Al-s] ${ }^{-1}$ ) & 9.4 & 10 & 9.7 & 10 & 8.7 & 9.4 \\
\hline DME partial pressure $(\mathrm{kPa})$ & 61 & 61 & 63 & 62 & 60 & 61 \\
\hline Co-feed partial pressure $(\mathrm{kPa})$ & 2 & 4 & - & 2 & 2 & 2 \\
\hline Net carbon conversion $(\%)$ & 64 & 52 & 47 & 51 & 55 & 49 \\
\hline \multicolumn{7}{|l|}{ Feed composition (in \%, on a carbon basis): } \\
\hline DME & 91 & 92 & 100 & 90 & 89 & 87 \\
\hline Co-feed & 9 & 8 & - & 10 & 11 & 13 \\
\hline \multicolumn{7}{|c|}{ Product distribution (in \%, on a carbon basis): } \\
\hline $\mathrm{C}_{2}$ & 1.1 & 1.1 & 1.1 & 2.3 & 2.5 & 1.3 \\
\hline $\mathrm{C}_{3}$ & 26.9 & 28.3 & 26.6 & 20.1 & 20.7 & 20.4 \\
\hline $\mathrm{C}_{4}-\mathrm{C}_{7}$ & 61.8 & 60.9 & 60.4 & 47.9 & 48.5 & 48.3 \\
\hline Methylbenzenes ${ }^{\mathrm{a}}$ & 1.2 & 0.6 & 1.5 & $21.4^{\mathrm{a}}$ & $19.4^{\mathrm{a}}$ & $21.7^{\mathrm{a}}$ \\
\hline Others $^{b}$ & 9.1 & 9.4 & 10.4 & 8.4 & 8.8 & 8.4 \\
\hline Ethene $/ 2 \mathrm{MBu}^{\mathrm{c}}$ & 0.14 & 0.14 & 0.15 & 0.42 & 0.45 & 0.22 \\
\hline $\mathrm{H} / \mathrm{C}$ in "Others" & 1.80 & 1.74 & 1.81 & 1.74 & 1.72 & 1.85 \\
\hline
\end{tabular}

${ }^{a}$ Reported methylbenzenes selectivity includes the unreacted co-feed.

$\mathrm{b}$ "Others" fraction includes $\mathrm{C}_{8}+$ hydrocarbons, except polymethylbenzenes.

${ }^{c}$ Ratio of the synthesis rates of ethene and 2-methylbutane +2 -methyl-2-butene.

d The hydrogen to carbon ratio $(\mathrm{H} / \mathrm{C})$ in "Others" fraction was calculated based on the difference in carbon and hydrogen content of known hydrocarbon species in the reaction effluent and the converted feed. 
Table 4. Reaction conditions, feed composition, and detailed product distribution, for the reaction of DME with olefin/aromatic cofeed on 3DOm-i MFI at $723 \mathrm{~K}$, total feed pressure $\sim 120 \mathrm{kPa}$, and 20 min time-on-stream. Methanol was considered as a reactant in the calculation of net carbon conversion.

\begin{tabular}{|c|c|c|c|c|c|}
\hline Co-feed & 1-Hexene & Propene & None & Toluene & $p$-Xylene \\
\hline Carbon space-velocity (mol C $[\mathrm{mol} \mathrm{Al-s}]^{-1}$ ) & 12 & 13 & 11 & 13 & 13 \\
\hline DME partial pressure $(\mathrm{kPa})$ & 61 & 60 & 62 & 62 & 61 \\
\hline Co-feed partial pressure $(\mathrm{kPa})$ & 2 & 4 & - & 2 & 2 \\
\hline Net carbon conversion $(\%)$ & 52 & 55 & 57 & 46 & 45 \\
\hline \multicolumn{6}{|l|}{ Feed composition (in \%, on a carbon basis) } \\
\hline DME & 91 & 91 & 100 & 91 & 89 \\
\hline Co-feed & 9 & 9 & - & 9 & 11 \\
\hline \multicolumn{6}{|l|}{ Product selectivity (in \%, on a carbon basis) } \\
\hline $\mathrm{C}_{2}$ & 2.2 & 2.3 & 2.8 & 7.5 & 8.3 \\
\hline $\mathrm{C}_{3}$ & 27.4 & 31.5 & 28.7 & 22.9 & 21.9 \\
\hline $\mathrm{C}_{4}-\mathrm{C}_{7}$ & 60.7 & 56.8 & 57.7 & 44.1 & 41.3 \\
\hline Methylbenzenes $^{\mathrm{a}}$ & 2.1 & 2.1 & 2.8 & $18.9^{\mathrm{a}}$ & $21.6^{\mathrm{a}}$ \\
\hline Others $^{b}$ & 7.7 & 7.3 & 8.0 & 6.6 & 6.9 \\
\hline Ethene $/ 2 \mathrm{MBu}^{\mathrm{c}}$ & 0.29 & 0.30 & 0.36 & 1.39 & 1.64 \\
\hline $\mathrm{H} / \mathrm{C}$ in "Others"d & 1.73 & 1.69 & 1.71 & 1.60 & 1.69 \\
\hline
\end{tabular}

${ }^{a}$ Reported methylbenzenes selectivity includes the unreacted co-feed.

$\mathrm{b}$ "Others" fraction includes $\mathrm{C}_{8}+$ hydrocarbons, except polymethylbenzenes.

${ }^{c}$ Ratio of the synthesis rates of ethene and 2-methylbutane +2 -methyl-2-butene.

d The hydrogen to carbon ratio (H/C) in "Others" fraction was calculated based on the difference in carbon and hydrogen content of known hydrocarbon species in the reaction effluent and the converted feed. 
Table 5. Reaction conditions, overall product distribution, and MB-free product distribution, for the reaction of propene with/without methylbenzenes (MBs) on SPP MFI at $723 \mathrm{~K}$, total feed pressure $\sim 120 \mathrm{kPa}$, and $20 \mathrm{~min}$ time-on-stream.

\begin{tabular}{|c|c|c|}
\hline Feed & Propene & Propene + MBs \\
\hline \multicolumn{3}{|c|}{ Feed composition (in \%, on a carbon basis): } \\
\hline Propene & 100 & 87 \\
\hline Methylbenzenes $^{\text {a }}$ & 0 & 13 \\
\hline \multicolumn{3}{|c|}{ Product selectivity (in \%, on a carbon basis): } \\
\hline $\mathrm{C}_{2}$ (Ethene) & $3.9(3.9)$ & $3.3(3.3)$ \\
\hline $\mathrm{C}_{3}$ (Propene) & $41.9(40.3)$ & $37.8(36.5)$ \\
\hline $\mathrm{C}_{4}-\mathrm{C}_{7}$ & 49.3 & 40.7 \\
\hline Methylbenzenes & 1.6 & 14.1 \\
\hline Others $^{b}$ & 3.2 & 4.1 \\
\hline \multicolumn{3}{|c|}{ MBs-free product selectivity (in \%, on a carbon basis): ${ }^{c}$} \\
\hline $\mathrm{C}_{2}$ (Ethene) & $4.0(4.0)$ & $3.8(3.8)$ \\
\hline $\mathrm{C}_{3}$ (Propene) & $42.6(41.0)$ & $44.0(42.5)$ \\
\hline $\mathrm{C}_{4}-\mathrm{C}_{7}$ & 50.2 & 47.4 \\
\hline Others $^{b}$ & 3.3 & 4.8 \\
\hline
\end{tabular}

${ }^{a}$ MBs co-feed comprised a mixture of $38 \mathrm{~mol} \%$ toluene, $33 \mathrm{~mol} \%$ p-xylene, and 29 mol\% 1,2,4-triMB.

b "Others" fraction includes $\mathrm{C}_{8}+$ hydrocarbons, except polymethylbenzenes.

${ }^{\mathrm{c}}$ MBs were not included in the calculation of product selectivity. 
Table 6. Feed composition and product distribution for the reaction of propene with/without ethene on SPP MFI at $723 \mathrm{~K}$, total feed pressure $\sim 115 \mathrm{kPa}$, and $20 \mathrm{~min}$ time-on-stream.

Feed Propene Propene + Ethene

\section{Feed composition (in \%, on a carbon basis):}

Propene

100

93

89

Ethene

$-$

6.9

11

Product distribution (in \%, on a carbon basis):

$\mathrm{C}_{2}$ (Ethene)

$\mathrm{C}_{3}$ (Propene)

$\mathrm{C}_{4}-\mathrm{C}_{7}$

Methylbenzenes

Others $^{\mathrm{a}}$
$3.3(3.2)$

$39.3(37.7)$

51.3

1.6

4.6
$7.8(7.8)$

$10.6(10.6)$

$37.7(36.2) \quad 38.6(37.4)$

49.1

46.0

1.1

4.3

1.0

a "Others" fraction includes $\mathrm{C}_{8}+$ hydrocarbons, except polymethylbenzenes. 


\section{Figures and captions}

Figure 1. Fractional change in selectivity toward $\mathrm{C}_{2}, \mathrm{C}_{3}, \mathrm{C}_{4}-\mathrm{C}_{7}$, methylbenzenes (MBs), and "Others" fraction, as the reaction temperature was increased from $623 \mathrm{~K}$ to $723 \mathrm{~K}$, for the catalytic reaction of DME on SPP MFI, 3DOm-i MFI, and Conv MFI samples, at 46-60\% net DME conversion, and 20 min time-on-stream.

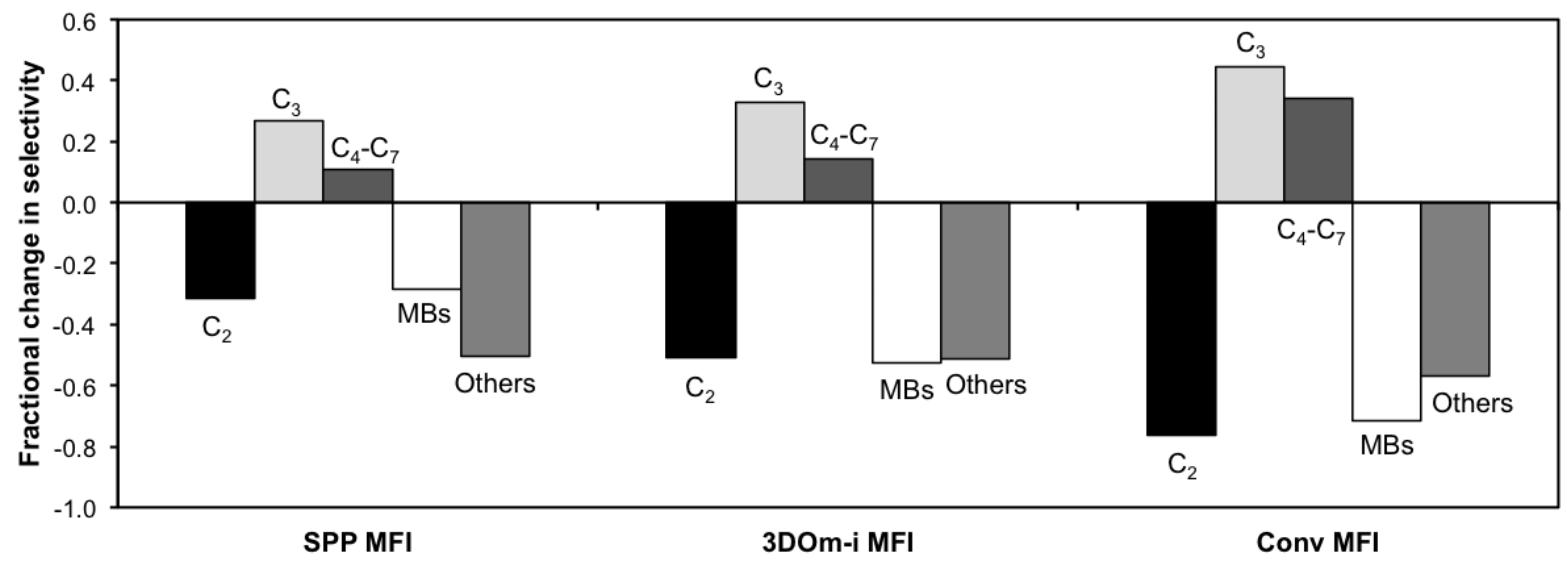


Figure 2. Effects of co-feeding 2,6-di-tert-butylpyridine (DTBP), and therefore the effects of passivating external Brønsted acid sites, on product selectivity of DME conversion on SPP MFI at $723 \mathrm{~K}$ and $42-43 \%$ net DME conversion. The data in the absence of DTBP are reported at 20 min time-on-stream while the data in the presence of DTBP are reported at 5 min time-onstream.

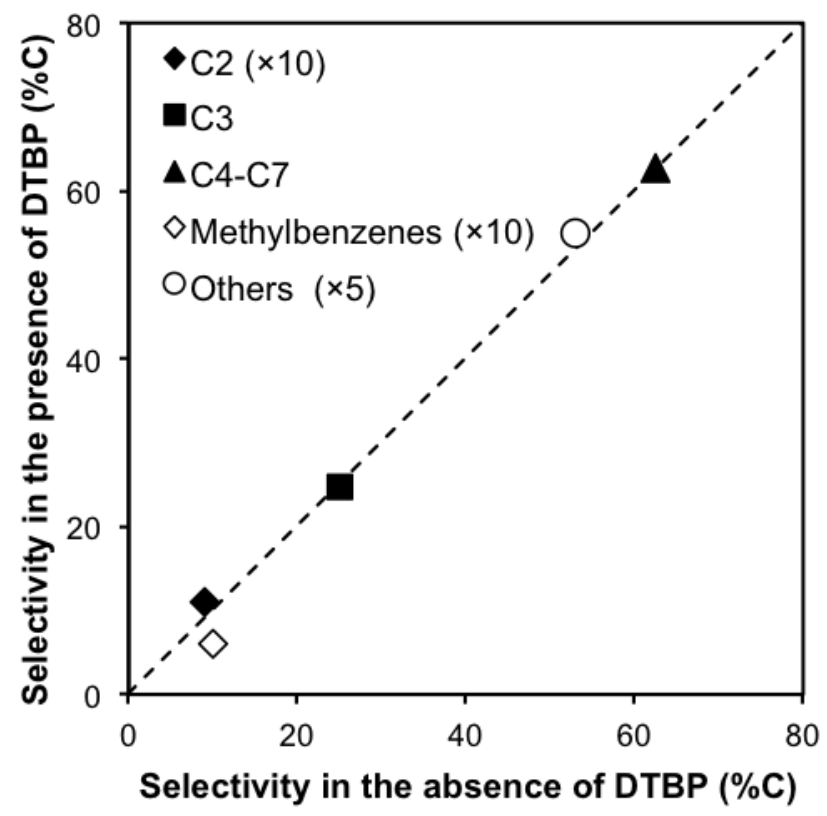


Figure 3. Ethene selectivity ( $\mathbf{\square}), 2 \mathrm{MBu}$ selectivity ( $\square$ ), and Ethene/2MBu, for the reaction of DME with olefin/aromatic co-feeds on SPP MFI at $723 \mathrm{~K}$, total feed pressure $\sim 120 \mathrm{kPa}, 47-64 \%$ net carbon conversion, and $20 \mathrm{~min}$ time-on-stream. Ethene $/ 2 \mathrm{MBu}$ is the ratio of synthesis rates of ethene and 2-methylbutane +2 -methyl-2-butene.

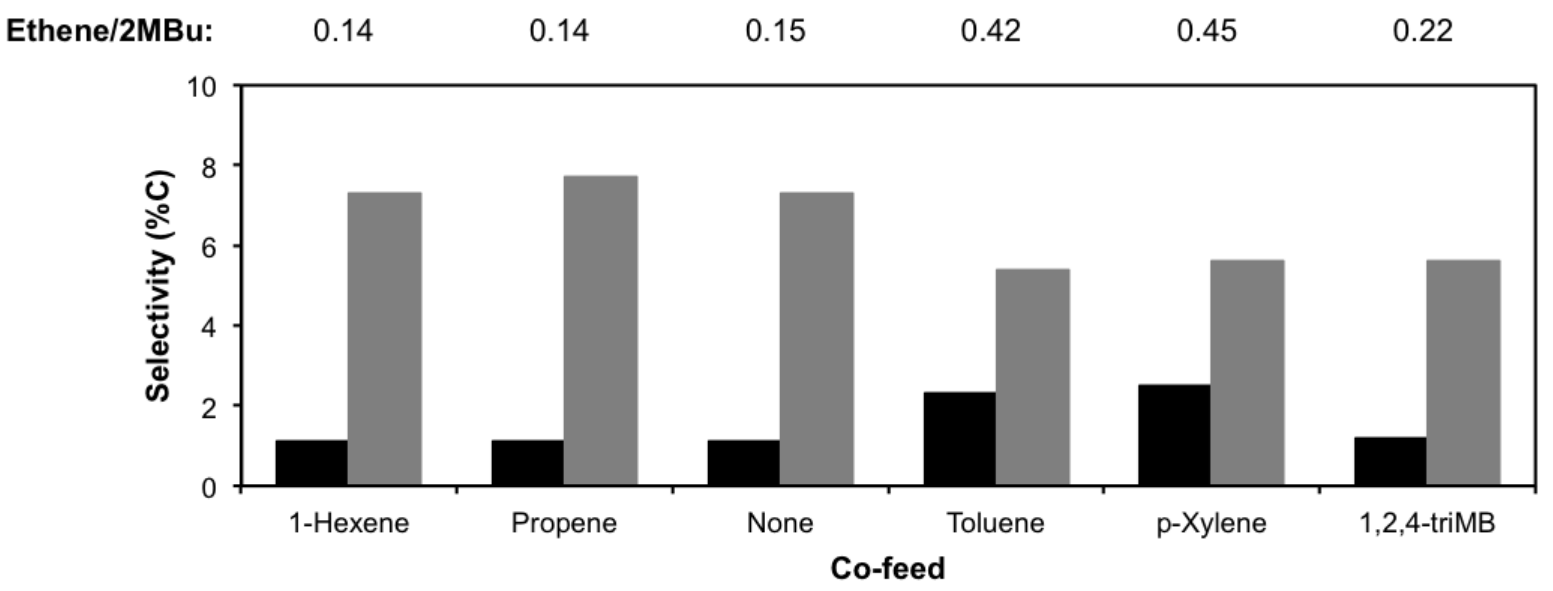


Figure 4. Ethene selectivity ( $\mathbf{\square}), 2 \mathrm{MBu}$ selectivity ( $\square$ ), and Ethene/2MBu, for the reaction of DME with olefin/aromatic co-feeds on 3DOm-i MFI at $723 \mathrm{~K}$, total feed pressure $\sim 120 \mathrm{kPa}$, 45$57 \%$ net carbon conversion, and $20 \mathrm{~min}$ time-on-stream. Ethene $/ 2 \mathrm{MBu}$ is the ratio of synthesis rates of ethene and 2-methylbutane +2 -methyl-2-butene.

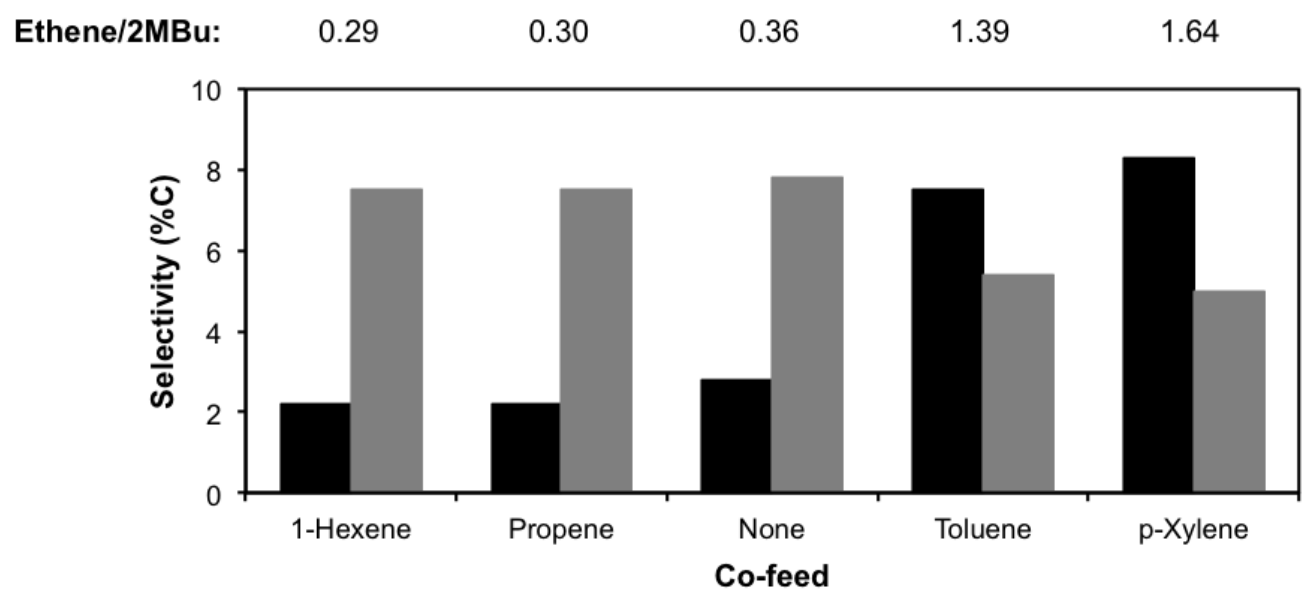


Figure 5. Effects of DME space-velocity (or DME space-time) on net DME conversion, for the reaction of DME on SPP MFI at $723 \mathrm{~K}$. DME space-velocity was varied from 0.3 to $17 \mathrm{~mol} \mathrm{C}$ $(\mathrm{mol} \mathrm{Al}-\mathrm{s})^{-1}$. Methanol was considered as a reactant in the calculation of net DME conversion. The fraction of catalyst bed acting as the 'first-stage' in the presence of DME/methanol as a function of DME space-time is also presented.

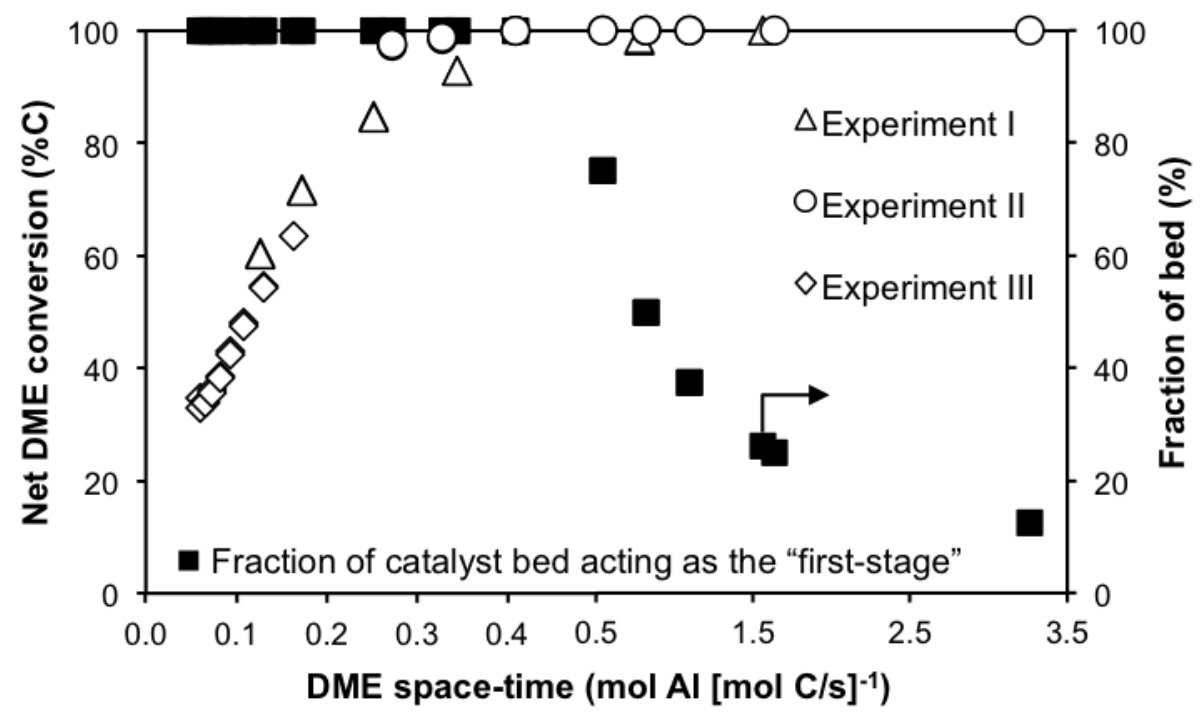


Figure 6. Effects of DME space-velocity (or DME space-time) on product distribution, for the reaction of DME on SPP MFI at $723 \mathrm{~K}$. DME space-velocity was varied from 0.3 to $17 \mathrm{~mol} \mathrm{C}$ $(\mathrm{mol} \mathrm{Al}-\mathrm{s})^{-1}$. (a) Product selectivity versus net DME conversion for data where DME conversion was $<100 \%$. Methanol was considered as a reactant in the calculation of net DME conversion (b) Product selectivity versus DME space-time (in mol Al $[\mathrm{mol} \mathrm{C} / \mathrm{s}]^{-1}$ ) for data where net DME conversion was 100\% and no DME/methanol was detected in the effluent.
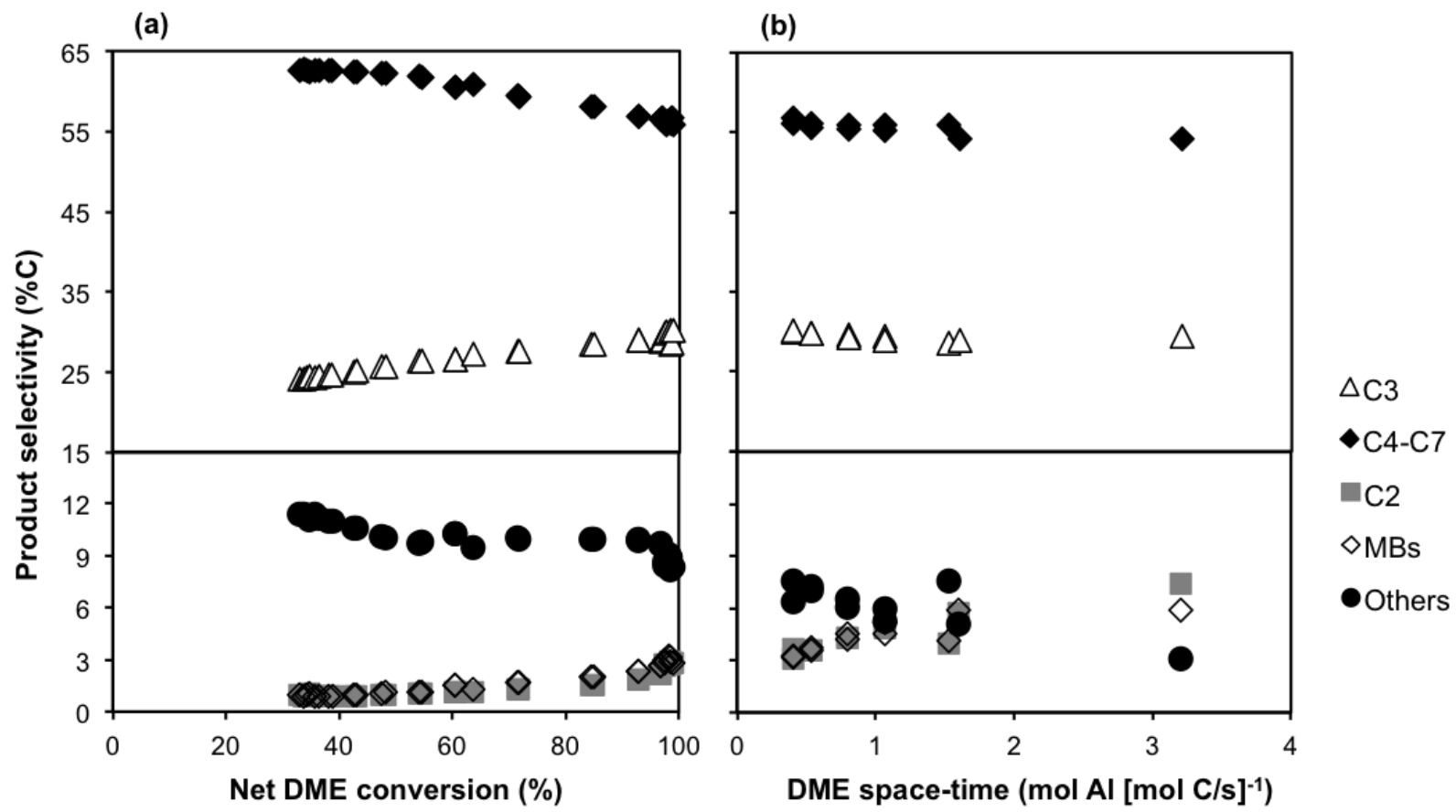
